CASE REPORT

\title{
Vacuum-assisted closure as a surgical assistant in life-threatening necrotizing fasciitis in children
}

\author{
FS Al-Subhi MD, RM Zuker MD FRCSC, WG Cole MD FRACS
}

FS Al-Subhi, RM Zuker, WG Cole. Vacuum-assisted closure as a surgical assistant in life-threatening necrotizing fasciitis in children. Can J Plast Surg 2010;18(4):139-142.

Necrotizing fasciitis is a severe soft tissue infection that can involve skin, subcutaneous fat, fascia and muscle. It can result in devastating sequelae including tissue necrosis, sepsis, toxic shock syndrome, cardiopulmonary collapse and death. To control rapidly spreading necrosis, early diagnosis and aggressive surgical treatment with extensive radical debridement of the affected areas is necessary, as well as systemic administration of broadspectrum antimicrobials and, very often, intensive care support.

The subatmospheric negative pressure dressing has been previously used in acute and complex wounds management. The concept of using vacuumassisted closure dressing as another management component is presented in the current article.

Key Words: Acute; Fasciitis; Necrotizing; Vacuum-assisted negative pressure
The present article describes the use of a subatmospheric 1 pressure dressing as an adjunct to serial debridement in the treatment of severe necrotizing fasciitis. These infections may begin as a small, reddish, painful spot or elevation on the skin. This quickly changes to a painful purplish patch that expands rapidly. The skin may become necrotic and break down. Visible expansion of the erythematous infected area may occur in less than $1 \mathrm{~h}$. Symptoms may include severe pain, fever, sweating, chills, nausea, dizziness, profound weakness and, finally, shock. Without treatment, death can occur rapidly.

\section{CASE PRESENTATION}

An eight-year-old girl was referred to the critical care unit at The Hospital for Sick Children (Toronto, Ontario) from another institution, with possible necrotizing fasciitis in her left lower extremity. She was known to our facility because she was previously surgically treated for obstetrical left brachial plexus injury. She had had a sore throat for one week, which was believed to be viral in origin. However, she also had a twoday history of leg pain. When she developed general weakness, she was taken to the local hospital. Despite systemic antibiotics, she did not improve. Within $8 \mathrm{~h}$, she was in septic shock. She received cardiopulmonary support measures, was intubated and transferred to the intensive care unit. She had significant swelling, redness and warmth over the entire left leg and up to the mid thigh, and her foot was gangrenous. It was clear that she had a rapidly progressive necrotizing infection on her left lower extremity. She was quickly taken to the operating room for surgical debridement (Figure 1).

After considerable discussion, a life-saving mid-thigh guillotine-type amputation was performed (Figure 2). The amputation stump had a simple pressure dressing applied. She

\section{Fermeture sous vide comme mesure chirurgicale d'appoint dans la fasciite nécrosante infantile à potentiel fatal} La fasciite nécrosante est une grave infection des tissus mous qui peut affecter
la peau, les tissus adipeux sous-cutanés, l'aponévrose et le muscle. Elle peut
entraîner des séquelles dévastatrices, comme la nécrose tissulaire, le sepsis, le
syndrome de choc toxique, le collapsus cardiopulmonaire et la mort. Pour
contrôler une nécrose fulminante, il faut poser un diagnostic rapide et
intervenir chirurgicalement dans les meilleurs délais en appliquant un
débridement radical élargi à la zone affectée, administrer des antibiotiques à
large spectre par voie systémique et très souvent, recourir aux soins intensifs.
Le pansement sous pression négative infra-atmosphérique avait déjà été utilisé
dans le traitement aigu de blessures complexes. Cet article présente le
concept de fermeture sous vide comme une autre composante thérapeutique.

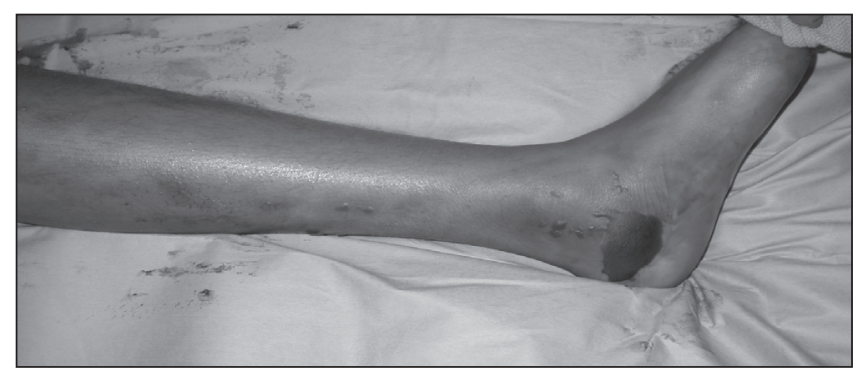

Figure 1) Left limb with necrotizing fasciitis before amputation

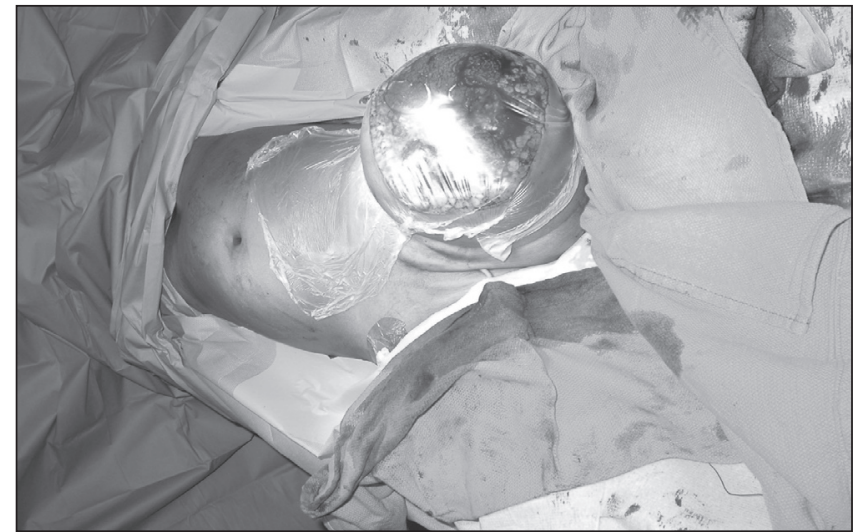

Figure 2) Amputated limb stump

was returned to the intensive care unit and, despite being very unstable, survived the night. The next morning, there was further progression of the infection to her groin and lower abdomen with redness, edema and severe tenderness. She also continued to require cardiopulmonary support. She was returned to the operating room that morning for further fascial

Divisions of Plastic Surgery and Orthopedic Surgery, The Hospital for Sick Children; Department of Surgery, University of Toronto, Toronto, Ontario

Correspondence and reprints: Dr RM Zuker, Division of Plastic Surgery, The Hospital for Sick Children, Suite 5416, 555 University Avenue,

Toronto, Ontario M5G 1X8. Telephone 416-813-6447, fax 416-813-6147, e-mail ronald.zuker@sickkids.ca 


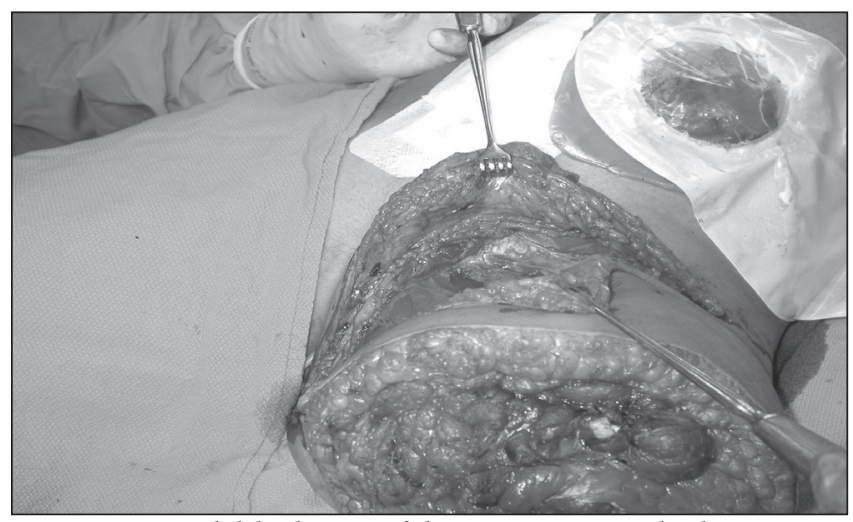

Figure 3) Second debridement of the stump, groin and colostomy

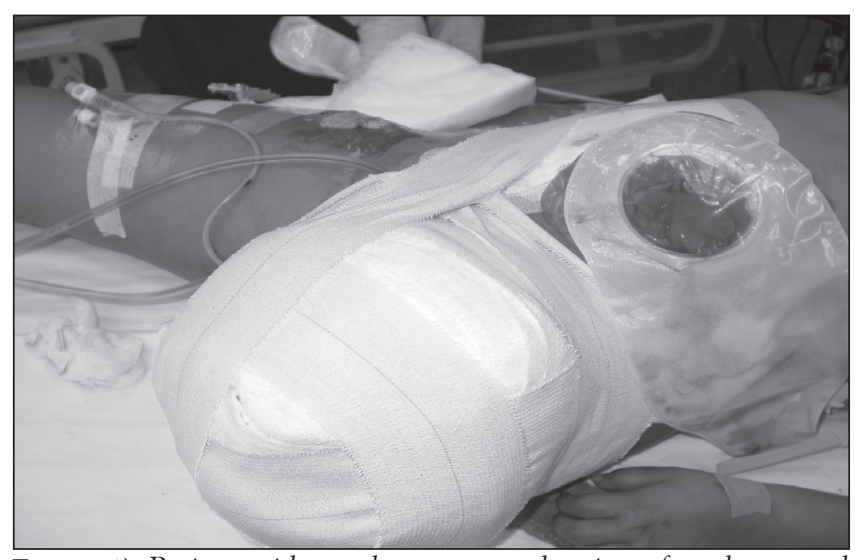

Figure 4) Patient with regular pressure dressing after the second surgical debridement

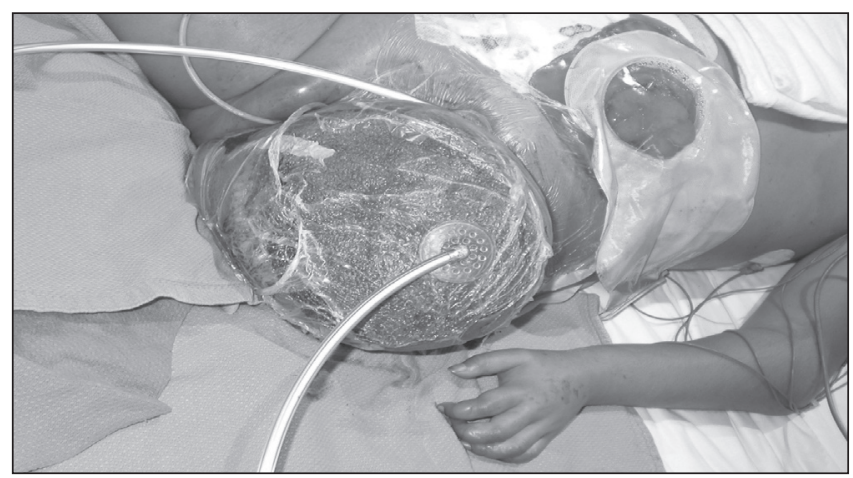

Figure 5) The amputated stump and groin wound treated with the vacuum dressing

excision down to the external oblique muscle up to the level of the umbilicus, and further excision of the necrotic groin skin (Figure 3). A laparotomy at the time did not reveal any intraabdominal involvement and a defunctioning colostomy was performed (Figure 4). The open wounds were clean with viable tissue, but were quite boggy. The thigh amputation stump and the large open groin wound were both treated with vacuum-assisted closure (VAC) dressing (KCI Medical Ltd, Canada), with a continuous subatmospheric suction pressure of $125 \mathrm{mmHg}$. The next day, the dressing was changed and the wounds were clean with no evidence of progressive disease (Figure 5). Systemically, the child continued to improve and was gradually transferred from an oscillating ventilator to a regular ventilator, and subsequently underwent extubation. The patient also improved from requiring high-dose inotropes to low dose and, eventually, none at all.

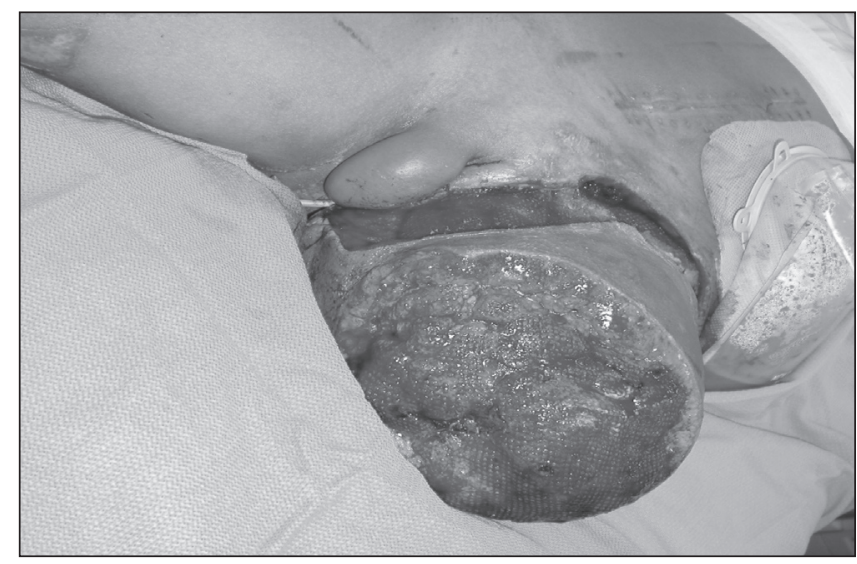

Figure 6) End of the first week; no further debridement required

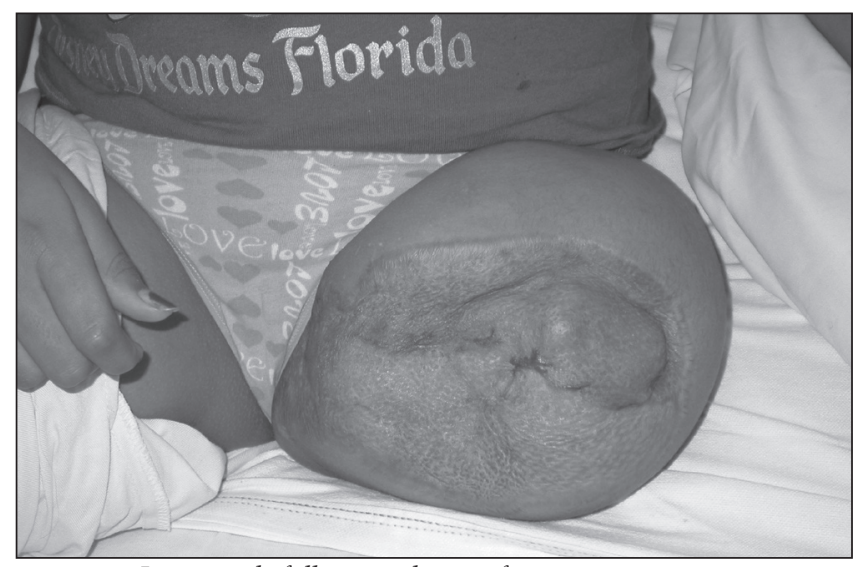

Figure 7) Late result following skin grafting to amputation stump

She was transferred to the plastic surgery ward for further management. Wound management with the VAC was continued, with dressing changes every two to three days. No further progression of the infection was noted, and no significant further debridement was necessary (Figure 6). The wound was closed on day 14 following admission, with regional flap and split-thickness skin graft covered with the VAC. Five days later, the dressing was changed, excellent skin graft take was noted and the VAC was discontinued. The VAC was used to reduce edema and possibly remove toxins from these large wounds. Because this was no longer necessary, the VAC was discontinued. Wound healing progressed favourably, and no further surgery was necessary (Figure 7).

\section{DISCUSSION}

Necrotizing soft tissue infections can be classified into two major groups: infections within the subcutaneous/fascial layers, and infections within the muscle itself. Necrotizing infections at the subcutaneous level are further differentiated into hemolytic streptococcal gangrene, necrotizing fasciitis, Clostridium fasciitis and anaerobic non-Clostridium fasciitis (1). Of particular note, necrotizing fasciitis is a rapidly progressive process, which is characterized by suppurative fasciitis, leading to vascular thrombosis and cutaneous gangrene. It is often accompanied by severe systemic toxicity, resulting in septictoxic shock and progressive (multi-) organ failure. In the muscle level group, infection by organisms such as Clostridium and Streptococcus could lead to myonecrosis and myositis. More than 20 years ago, the literature reported the mortality 
TABLE 1

Indication for the use of subatmospheric pressure dressing as proposed by Argenta et al (8)

Chronic wounds management
Acute wounds management
Sternal infections and mediastinitis
Abdominal wall defects
Full-thickness defects
Partial-thickness defects
Enterocutaneous fistula
Perineal wounds
Extremity and orthopedic trauma
Diabetic foot disease
Skin grafting with vacuum-assisted closure
Degloving injuries
Grafting over bone (preparing for skin grafting over bone)
Colonization of a synthetic matrix
Burns

rate to be as high as $52 \%$, with an amputation rate of $36 \%$ (1); however, this mortality rate has decreased over the years to $35 \%$. This may be explained by improved awareness, earlier diagnosis and improvement in treatment modalities (2). Fortunately, in children, the mortality rate is much lower (3).

In a major study (1) that assessed treatment approaches, the mean time to appropriate surgical therapy was 1.9 days. Operations performed more than $24 \mathrm{~h}$ after recognition of infection resulted in 70\% mortality versus 36\% mortality when operations were performed less than $24 \mathrm{~h}$ after recognition. A less extensive operation to conserve tissue can result in $71 \%$ mortality versus a $43 \%$ mortality with initial radical surgery, which encompasses all devitalized tissue.

Necrotizing fasciitis can be classified as idiopathic, in which the cause is uncertain or is principally a monomicrobial infection usually caused by Streptococcus pyogenes. This commonly occurs in the extremities. The other form - termed secondary necrotizing fasciitis - follows trauma, surgical wounds or any trivial body infection. The involved organisms can be aerobic or anaerobic bacteria or, occasionally, a synergistic polymicrobial combination (2). In children, secondary necrotizing fasciitis can be attributable to any secondary injury (eg, varicella lesions, omphalitis, extremity trauma, malnutrition, boils and intravenous cannulation). The mortality rate is always high, regardless of the etiology $(4,5)$.

To control rapidly progressing necrosis, early diagnosis and urgent surgical treatment is required. This must be aggressive, with extensive radical debridement of the affected areas, amputation as necessary, and followed by intensive care unit support. Systemic administration of broad-spectrum antimicrobials is an important supportive therapy, and the use of hyperbaric oxygen therapy is believed to be helpful. We recommend the use of subatmospheric pressure dressing as a surgical assistant to the management of necrotizing fasciitis.

The VAC (subatmospheric pressure dressing) is an adjunctive therapy system that uses controlled negative pressure (vacuum) to help promote wound healing. This is accompanied by suctioning of exudate from open wounds and, more particularly, a system for cleaning residual contaminants through a

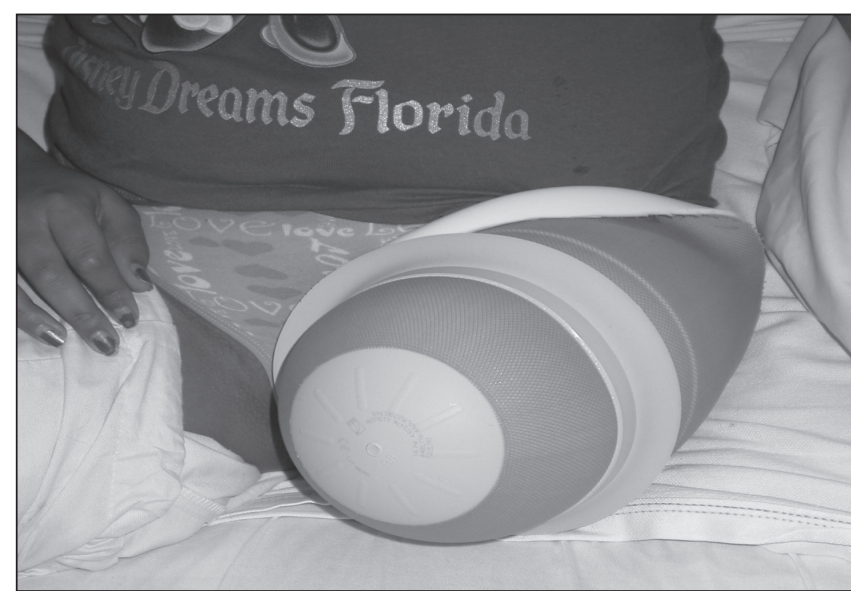

Figure 8) Stump with silastic sleeve, which holds prosthesis with suction

sealed dressing and tubing, which is connected to a collection container.

The subatmospheric pressure dressing was found to be effective in managing nonhealing limb wounds secondary to surgical treatment for patients suffering from acute necrotizing fasciitis and other difficult wounds. VAC has previously been found to be an extremely efficacious modality for treating chronic and difficult wounds (6), and has also been shown to reduce the time between debridement and application of the VAC dressing and wound healing (7).

In 2006, Argenta et al (8) outlined the use of VAC dressing for various wounds (Table 1 ). To this list we would add acute necrotizing fasciitis, with the $\mathrm{VAC}$ dressing providing a surgical assist. It is certainly not a definitive treatment, but an adjunct that can be effectively used after adequate surgical debridement. It decreases edema, reduces infected exudate, encourages wound healing and assists in skin graft take and wound closure.

Can we now add the VAC to the list of active surgical assistants for the treatment of necrotizing fasciitis?

The mechanism of action of VAC in stimulating granulation tissue and improving wound healing is still being worked out. However, it seems that the reduction in tissue edema and exudate from the wound should also reduce the bacterial load and, thus, help in the overall management of necrotizing fasciitis and not only the open wound component.

The guillotine mid-thigh amputation was a rapid life-saving approach. The stump was successfully grafted. Previously, this type of stump would have been a liability because end-weight bearing would be difficult. However, current prostheses utilize total contact with proximal weight bearing, thus, avoiding the end-weight bearing stump. The use of silicone liners and sleeves providing total contact avoid shearing and pressure forces. They also apply pressure on the grafted tissue, thus assisting in graft maturation. The actual end of the stump can be largely disregarded thanks to these newer prostheses (Figure 8).

\section{CONCLUSION}

We believe that in necrotizing fasciitis, the subatmospheric pressure VAC dressing can be an important adjunct following 
surgical treatment. Not only does it reduce edema, but it may also remove virulent organisms and toxins that contribute to the ongoing effects of this disease. Will this reduce the progression of the disease process? One can only speculate. However, from our surgical perspective, this seems likely and from our experience in this complex case, it was very helpful.

CONFLICTS OF INTEREST: The authors have no conflicts of interest to declare or any commercial associations to disclose.

\section{REFERENCES}

1. Freischlag JA, Ajalat G, Busuttil RW. Treatment of necrotizing soft tissue infections. The need for a new approach. Am J Surg 1985;149:751-5.

2. Taviloglu K, Cabioglu N, Cagatay A, et al. Idiopathic necrotizing fasciitis: Risk factors and strategies for management. Am Surg 2005;71:315-20.
3. Fustes-Morales A, Gutierrez-Castrellon P, Duran-Mckinster C, Orozco-Covarrubias L, Tamayo-Sanchez L, Ruiz-Maldonado R. Necrotizing fasciitis: Report of 39 pediatric cases. Arch Dermatol 2002;138:893-9.

4. Moss RL, Musemeche CA, Kosloske AM. Necrotizing fasciitis in children: Prompt recognition and aggressive therapy improve survival. J Pediatr Surg 1996;31:1142-6.

5. Legbo JN, Shehu BB. Necrotising fasciitis: Experience with 32 children. Ann Trop Paediatr 2005;25:183-9.

6. Huang WS, Hsieh SC, Hsieh CS, Schoung JY, Huang T. Use of vacuum-assisted wound closure to manage limb wounds in patients suffering from acute necrotizing fasciitis. Asian J Surg 2006;29:135-9.

7. Argenta LC, Morykwas MJ. Vacuum-assisted closure: A new method for wound control and treatment: Clinical experience. Ann Plast Surg 1997;38:563-76; discussion 577.

8. Argenta LC, Morykwas MJ, Marks MW, DeFranzo AJ, Molnar JA, David LR. Vacuum-assisted closure: State of clinic art. Plast Reconstr Surg 2006;117(Suppl 7):127S-142S. 